\title{
IMPLEMENTATION OF SIX SIGMA METHODOLOGY IN CONSTRUCTION FOR PROCESS IMPROVEMENT
}

\author{
Shweta P. Chaudhari \\ Civil and Environmental Engineering Department, Veermata Jijabai Technological Institute \\ (VJTI), Mumbai, India
}

Dr. A. S. Wayal

Associate Professor and Head, Civil and Environmental Engineering Department, Veermata Jijabai Technological Institute (VJTI), Mumbai, India

\begin{abstract}
Achieving specified levels of quality in the construction industry has always been a problem. A successful construction project is expected to create a balance between cost, time and quality. Also, there is a huge scope to reduce the costs associated with the wastage of resources and rework during the execution of construction projects. To obtain quality construction, it is necessary to focus on process improvement. Construction industry is looking to other industries such as manufacturing to examine the effectiveness of measuring and monitoring tools. Six Sigma is one of them. Six Sigma is a statistics-based process improvement technique. This paper includes a case study of a residential building where Six Sigma approach is used for measuring and improving the process of blockwork on site. The purpose of this study is to minimize the wastage, rework, defects and obtain a quality process using Six Sigma methodology. During the implementation of Six Sigma, considerable improvements were observed in the ongoing process on site. And the same can be implemented on other processes involved in the construction of the entire building in order to improve the construction process as a whole.
\end{abstract}

Keywords: Process improvement, quality, Six Sigma, Construction Management.

Cite this Article: Shweta P. Chaudhari and Dr. A.S. Wayal, Implementation of Six Sigma Methodology in Construction for Process Improvement. International Journal of Civil Engineering and Technology, 11(5), 2020, pp. 57-66.

https://iaeme.com/Home/issue/IJCIET?Volume=11\&Issue=5

\section{INTRODUCTION}

\subsection{General}

Quality is one of the critical factors in the success of construction projects. Improvement in the quality of construction projects is linked with quality management throughout the project life cycle (D. Ashokkumar, 2014). Quality management during the execution or construction 
phase contributes significantly to the quality of the finished outcome of the entire construction process. The quality of the entire project depends upon the quality of every single process involved in the making of the project. Therefore, it is necessary to focus on processes.

The concept of quality management and process improvement is to ensure efforts to achieve the required level of quality for the product. The aim of implementing process improvement techniques is to do things right at the first time itself so that the time and costs associated with the repair work and/or rework are saved. Achieving a quality process aims at obtaining a product of desired quality by avoiding all the possible mistakes in order to avoid the need for rework and by performing the process with as minimum wastage of resources as possible.

\subsection{Six Sigma}

To obtain a high-quality product as per customers' requirement and to reduce the cost of rework can be put in other words as 'to produce a low defect product'. Six Sigma is a methodology that measures a process in terms of defects. The central idea of Six Sigma approach is that if the defects in the process can be measured, the ways to eliminate them can be systematically figured out and a near- perfect quality level can be achieved.

Six Sigma was first used in 1985 by Bill Smith of Motorola to decrease cost, increase quality by improving process and reduce the production time. The Six Sigma principle can be represented on a normally distributed product quality distribution curve. When the mean is located at the centre of the normal distribution curve, the lower and upper limits are six times the standard deviation (sigma) from the centre line. In other words, the range of lower and upper limit defect is +/- 6 sigma from the mean. (Sneha P. Sawant, 2014)

The Six sigma principle has been an effective statistical-based methodology in measuring the defect rate in an attempt to maintain a high-standard quality level. (Seung Heon Han, 2008)

If a process is operating at Six Sigma level, it means that there are only 3.4 defects per million opportunities (DPMO). Operating at Six Sigma level means products and services are almost $99.99966 \%$ perfect. It analyses the capability of the process, aims at eliminating defects and at stabilizing the process by reducing or eliminating variations.

Various authors have defined Six Sigma in different ways. All the various definitions can be summarized into following two aspects:

- Six Sigma is a statistical measure used to measure the performance of processes or products against customer requirements.

- Six Sigma is a cultural belief system and a management philosophy that leads the organization towards world-class business performance by increasing customer satisfaction and enhancing bottom lines based on factual decision making. (Low Sui Pheng, 2004)

\section{PROCESS IMPROVEMENT USING SIX SIGMA}

Six Sigma is a statistics-based methodology. However, it is not merely statistics, but it helps you to understand the value of statistics and how to use them, in order to make rational and measurable decisions about the concerned processes. Six Sigma methodology uses statistical tools to identify the vital factors which matter the most for improving the process quality and producing acceptable and satisfactory results. Six Sigma is a disciplined extension of TQM. (Greg Brue, 2002)

Six Sigma uses a five-phase methodology for reducing defects and improving the quality of process. The methodology is DMAIC (Define, Measure, Analyze, Improve, Control). 
Define: Define the problems and the goals, deliverables to customers.

Measure: Measure the current performance of the process.

Analyze: Analyze and determine the root causes of the defects.

Improve: Improve the process to eliminate defects.

Control: Control the performance of the process.

(Greg Brue, 2002)

Six Sigma measures the performance of process based on the number of defects per million opportunities (DPMO), which is calculated using the formula:

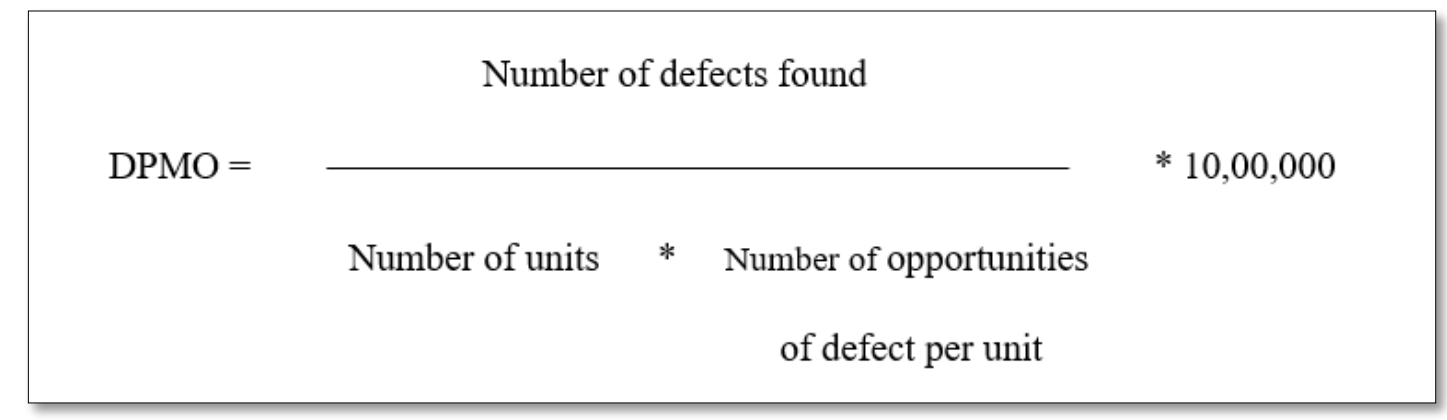

From the DPMO value, we can work out the Sigma level of the process from DPMO to Sigma conversion tables which are readily available.

\section{IMPLEMENTATION OF SIX SIGMA IN CONSTRUCTION: CASE STUDY}

To implement Six Sigma for a construction process improvement, a residential building is considered. The problem to work on i.e. the process to improve was decided by consulting the site engineer, project manager and other site personnel on the selected site. The five-phase approach used is described below in brief.

\subsection{Define Phase}

\subsubsection{Problem identification and definition}

- Problem: Defects in the process of blockwork in walls leading to wastage of resources and need for rework in future

- Goal: To identify various defects in block walls on site and to work on reducing the occurrences of the said defects with the involvement of all site personnel dealing with the process.

\subsubsection{SIPOC Analysis}

SIPOC analysis is a way of process mapping. This helps us to understand every aspect of inputs and outputs. It helps to document the process so that you can maintain control and reduce variation due to changes over time. It is basically to study the process we are working on taking into account various associated aspects like the supplier, inputs, process, output and customer.

Table 1 shows SIPOC Analysis of blockwork in walls on the selected site, done through communication with site personnel and observation. 
Table 1 SIPOC Analysis for process of blockwork on site

\begin{tabular}{|c|c|c|c|c|}
\hline Supplier & Input & Process & Output & Customer \\
\hline Builder & $\begin{array}{l}\text { Concrete blocks, } \\
\text { Adhesive } \\
\text { chemical, water, } \\
\text { Plumb bob, } \\
\text { Measuring tape, } \\
\text { trowel, cleaning } \\
\text { cloth, etc. }\end{array}$ & $\begin{array}{l}\text { Visual inspection of blocks } \\
\text { Surface preparation (Roughen the surface } \\
\text { by pouring some cement slurry) } \\
\text { Shuttering/formwork for Damp Proofing } \\
\text { Course (DPC) } \\
\text { Pouring PCC (1:2:4) upto } 200 \text { mm height } \\
\text { Allow the DPC layer to set } \\
\text { Clean the DPC surface and the faces of } \\
\text { columns and beams before starting out } \\
\text { block laying process } \\
\text { Mix adhesive powder and appropriate } \\
\text { quantity of water to form a paste with } \\
\text { suitable consistency } \\
\text { Wet block before laying } \\
\text { Apply adhesive paste on the DPC layer } \\
\text { and on the column face at the starting } \\
\text { point. And also on the lower side of the } \\
\text { block } \\
\text { Place the block } \\
\text { Apply adhesive on the face of the block } \\
\text { where next block is to be placed. } \\
\text { Compact and fix the block. } \\
\text { Continue the blockwork upto } 1 \text { m height } \\
\text { maintaining a stretcher bond. } \\
\text { Construct shuttering for about } 100 \text { - } 150 \\
\text { mm height of RCC band/Patli } \\
\text { Pour PCC and lay two steel bars } \\
\text { horizontally and pour PCC again and } \\
\text { discontinue the blockwork for that } \\
\text { particular wall for the day. }\end{array}$ & Concrete block wall & plasterers \\
\hline
\end{tabular}

\subsubsection{Opportunities for Defects}

The opportunities of defects in the block walls prior to plastering are:

- Voids (joints not filled properly)

- Joint between masonry and RCC not filled properly

- Adhesive drips

- Inaccurate alignment of blocks

- Broken blocks

- Cracks along joints or in blocks

- DPC layer not being in perfect dimensions

- Damages done at the time of electric fitting installations

\subsection{Measure Phase}

To measure the number of defects for the above listed opportunities, the determined number of units (120 units of walls of dimensions $0.6 \times 2.3 \mathrm{~m}$ ) were observed carefully and the defects were counted. The defects were detected by visual inspection, measurements, and tools like plumb bob or levels. While measuring defects, if a unit was found defective for an opportunity, then it was counted as one defect for that particular opportunity. Defects were defined as per requirement. 
Shweta P. Chaudhari and Dr. A.S. Wayal

Table 2 Defect Count

\begin{tabular}{|c|c|c|c|c|c|c|}
\hline & Voids & Adhesive drips & Broken blocks & $\begin{array}{c}\text { Inaccurate } \\
\text { alignment }\end{array}$ & Cracks & $\begin{array}{c}\text { DPC out of } \\
\text { dimensions }\end{array}$ \\
\hline $\begin{array}{c}\text { Total number of } \\
\text { defects }\end{array}$ & 32 & 27 & 25 & 9 & 4 & 9 \\
\hline
\end{tabular}

\subsection{Analyze Phase}

In this phase, the analysis of the causes of defects mentioned earlier was done. Cause \& Effect diagrams were prepared. Also, FMEA (Failure Mode Effect Analysis) was performed to help understand the causes, effects, severity, detectability and thus risk priority number of the defects and also the corresponding recommended actions and responsibilities were assigned.

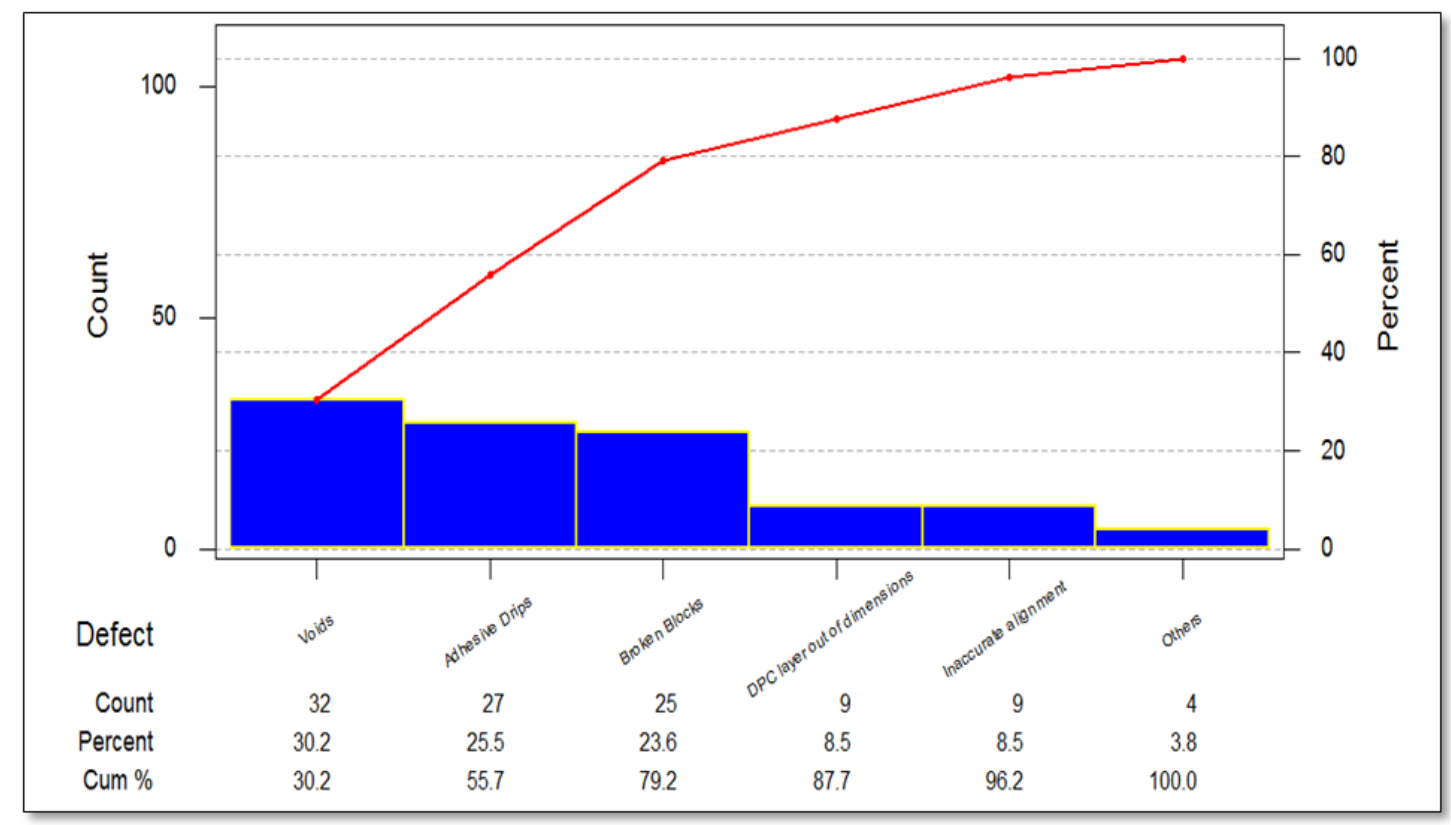

Figure 1 Pareto chart for defect count for various opportunities

Figure 1 shows Pareto chart for the defect count represented in table 2. It shows percentage of individual defects along with cumulative percentage of all defects from highest occurring to least occurring defect. From this it can be concluded voids, adhesive drips and broken blocks constitute the most of defects i.e. 79.2\%. It means, we have to work on eliminating these defects to get the process to improve by about $80 \%$. Hence, the first four defects were selected for calculation and improvement phase.

Number of units observed $=120$

Unit size $=0.6 \mathrm{~m} \times 2.3 \mathrm{~m}$

opportunities for defects $=4$

Total opportunities for defects $=120 \times 4=480$

Number of defects found $=93$

DPMO $=(93 / 480) \times 10^{6}=193750$

Based on the DPMO to Sigma conversion table,

At $\mathrm{DPMO}=193750, \sigma=2.365$ 


\subsubsection{Possible root causes for defects}

The possible root causes of each defect or error in concern were listed out using tools such as brainstorming and communication with the people actually working on the process and observing the actual practice of block laying on the site.

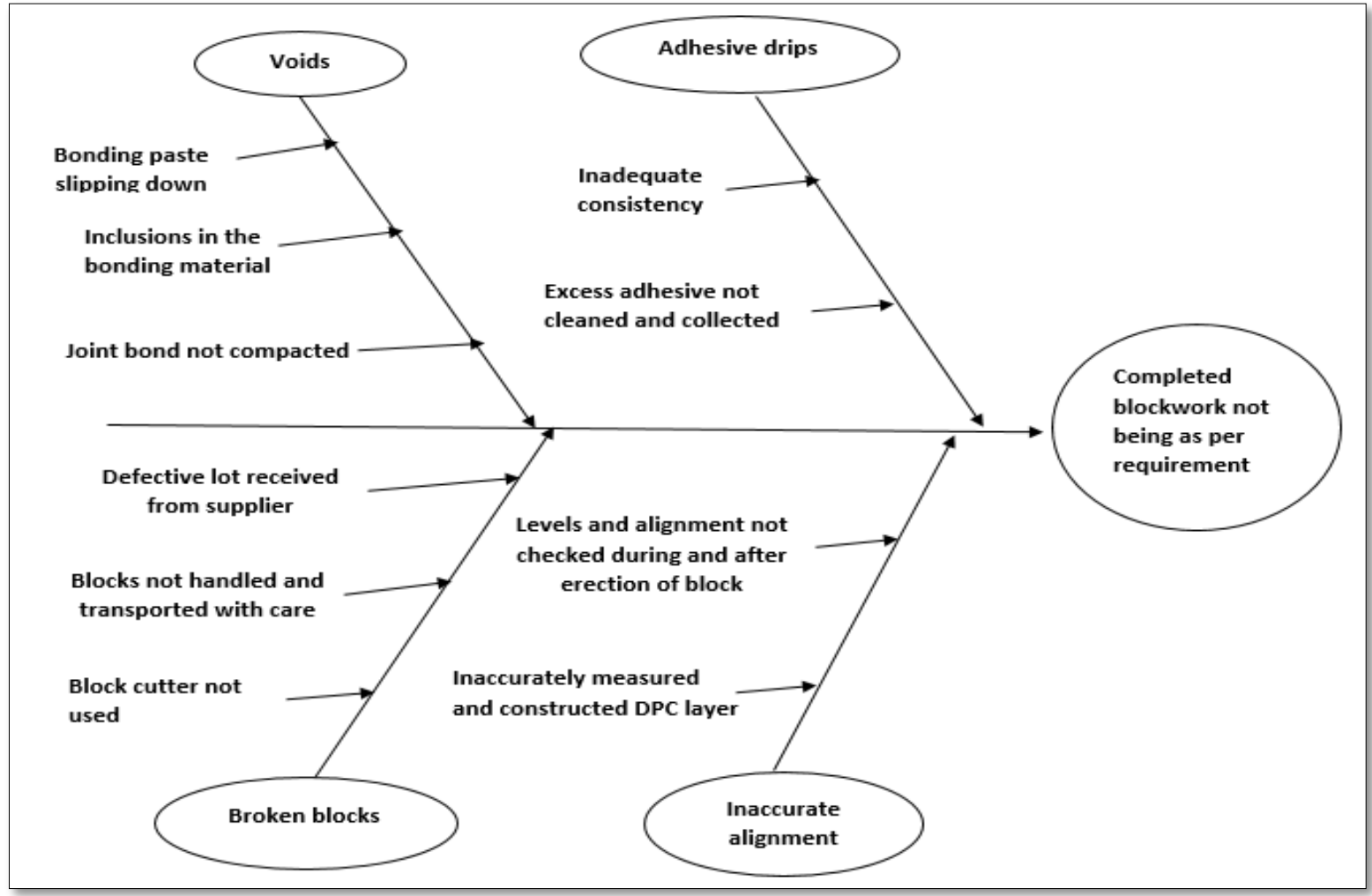

Figure 2 Cause and effect diagram

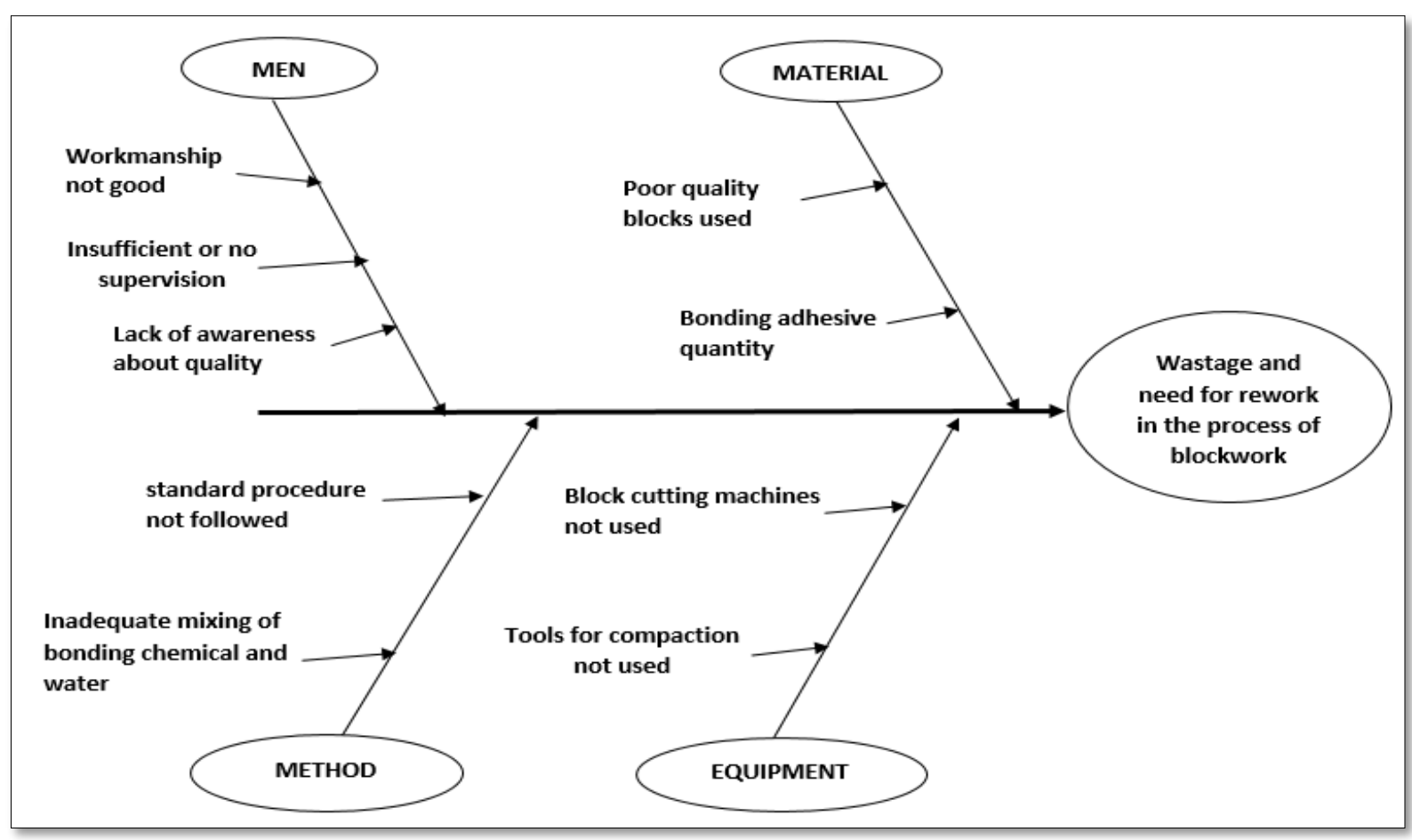

Figure 3 Cause and effect diagram 
Figure 2 and Figure 3 show cause and effect diagram for the found defects. Cause and effect diagram helps to determine areas to work on for betterment of process to minimize defects in the finished block walls. Here, the possible causes of the problem were determined after discussions with the team members, brainstorming and multi-voting. Figure 1 represents with their corresponding root causes leading to the blockwork not being as per required level of quality. Figure 2 shows distribution of causes in four major categories viz. Men, Material, Method, and Equipment leading to need for rework and wastage of resources.

\subsubsection{Cost of Poor Quality}

In any kind of work, there are costs associated with poor quality. In case of blockwork on sites, if it is found that the completed blockwork is of poor quality or in other words, it is simply not according to the standard requirements i.e. showing one of the above types of errors or defects, additional costs will be involved in repairing the found damages. Cost of poor quality may consist of:

COPQ $=$ cost of material wasted + cost of material for rework + cost of labor for repair and rework + cost associated with delay

The bonding adhesive used on the site sets quickly and thus if issues such as improper alignment of blocks or DPC layer happen, it needs to be levelled by chipping the unwanted parts, which involves costs of labor, material, etc. Sometimes, depending upon the severity of alignment issue, the masonry may have to be dismantled (however, the need for dismantling is very rare.), which leads to loss of cost of material and cost of rework.

By reducing voids in the masonry in the first time itself, the extra work of refilling the same is saved along with the cost associated with it i.e. cost of adhesive chemical, cost of labor and cost associated with delay. To fill the voids, the mix has to be prepared again. Even for a small number of voids, $1 / 2$ to $1 \mathrm{~kg}$ of adhesive is prepared a part of which ultimately goes to waste. Also, it causes delay in subsequent processes.

By immediately cleaning and collecting the excess adhesive will save costs associated with time required to clean the masonry surface before plastering and the cost of adhesive wasted due to not reusing it. Sometimes, if the drips are not cleaned and are covered up with plastering, however, it will lead to non-homogeneity in the plaster masonry bond.

\subsection{Improve Phase}

This phase involves working on the improvement of the current practices on site that will lead to reduction in the previously found defects. The areas of improvement were determined based on the root causes derived from the cause and effect diagram worked out in the Analyze phase. Also, in continuation with the FMEA, by multi-voting and using the knowledge of process doers, areas of improvement and ways of improvement were finalized.

It was decided that the areas of improvement in the current practice were:

- Having predetermined and consistent mix of quantities of bonding chemical and water.

- Tools such as wooden or rubber mallet be used to tamp the block to shove it properly in place and so that the applied adhesive gets well compacted and the excess comes out.

- Training programs to be arranged for workers.

- Better or more frequent supervision be provided. 


\subsubsection{Steps taken for Improvement}

- An external training program was arranged for workers.

- Demonstrative training was included as a part of training sessions arranged on site

- To have a consistent mix of the bonding material, different proportions of adhesive chemical and water mix were tried and outputs were observed.

- The manual of Magicbond block joining adhesive suggests using about 14-16 liters of water for a $40 \mathrm{~kg}$ bag.

- By experimentation, 250-300 $\mathrm{ml}$ water for $1 \mathrm{~kg}$ of adhesive chemical was finalized to be used as a constant proportion.

- It is difficult to accurately measure the quantity of materials mixed in the present labor culture. However, it was advised to use any kind of container available on site to measure mix proportions and maintain it throughout the work.

After implementing some of the suggested improvements, the sigma level was found to have increased from 2.365 to 3.305 .

\subsection{Control Phase}

Control phase will include Implementing process control on the improvement process to check whether expected improvements have been achieved with the help of a control plan. A control plan is the documented description of procedures, checks or activities necessary to verify that the process output conforms to the desired level of quality. In this case, the responsibility of the continuous implementation of the suggested improvements was handed over to the site management.

\section{RESULTS AND DISCUSSION}

After implementing the decided improvements, same number of units were again observed for any defects and the defect count is given below.

Table 3 Defect count after Improve phase

\begin{tabular}{|c|c|c|c|c|}
\hline Unit & Voids & Adhesive drips & Broken blocks & $\begin{array}{c}\text { Inaccurate } \\
\text { alignment }\end{array}$ \\
\hline $\begin{array}{c}\text { Total number of } \\
\text { defects }\end{array}$ & 8 & 5 & 4 & 0 \\
\hline
\end{tabular}

Table 3 shows that the implementation of DMAIC methodology of Six Sigma resulted in reduction of defects previously found in the block masonry work.

The Sigma level of the process was increased from an initial value of 2.365 to 3.305 after the implementation of the five-phase methodology. 


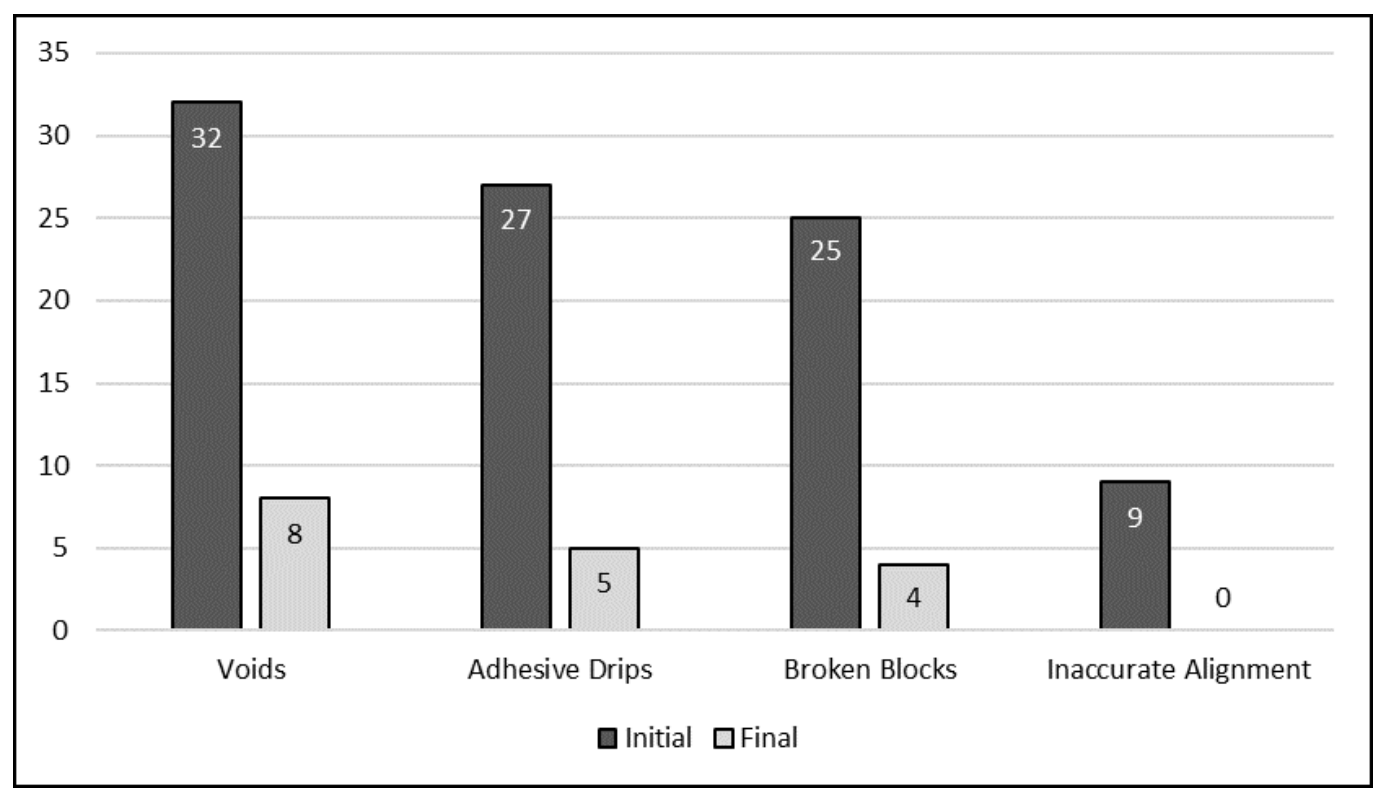

Figure 4 Comparative Graph of defects before and after Improve phase

From the graph in figure 4, it can be seen that the voids have been reduced by $20 \%$, Adhesive drips by about $18 \%$, Use of broken blocks was reduced by $17.5 \%$ and the issues with inaccurate alignment were not found in the inspected units of blockmasonry.

With the reduction in defect count, consumption of material was reduced for the same amount of work as compared to earlier practice as the wastage of material was reduced. Also, time and labour efforts were saved.

Also, with the reduction in wastage and need for repair and rework, the corresponding costs are saved.

\section{CONCLUSION}

Various little aspects have considerable impact on the quality of processes and the final output of the process. Most of the defects found in the process were related to human errors. Thus, with proper training, careful supervision and making easy changes in the working method, the defects can be eliminated. It can be seen that the Six Sigma approach for improvement can be very helpful in maintaining the process quality and saving various costs associated with poor quality, if implemented effectively. It was found that during and after the implementation of Improve phase, considerable improvement could be observed in the finished block masonry walls on site. With the increase in Sigma level of the process, cost of poor quality, cost of labour, wastage of resources including time are reduced.

\section{DATA AVAILABILITY STATEMENT}

All data generated and analysed during the study is included in the submitted article itself.

\section{REFERENCES}

[1] D. Ashokkumar, "Study of Quality Management in Construction Industry", International Conference on Engineering Technology and Science-(ICETS) 2014

[2] Seung Heon Han, Myung Jin Chae, Keon Soon; and Ho Dong, "Six Sigma-Based Approach to Improve Performance in Construction Operations", Journal of Management in Engineering, 2008; pp. 21-31 
Implementation of Six Sigma Methodology in Construction for Process Improvement

[3] Sneha P. Sawant1and Smita V. Pataskar, "Applying Six Sigma Principles in Construction Industry for Quality Improvement", International Conference on Advances in Engineering and Technology - ICAET-2014

[4] Greg Brue, Six Sigma for Managers, Tata McGraw Hill Publishing Co.Ltd. 2002

[5] Low Sui Pheng and Mok Sze Hui, Implementing and Applying Six Sigma in Construction, Journal of Construction Engineering and Management, 2004; pp. 482-489 